Revista do CESP, Belo Horizonte, v. 37, n. 58, p. 75-91, 2017

\title{
Equivocidade da língua e alteridade do sujeito: a poesia de Fernando Pessoa
}

\section{Language Equivocity and Subject's Alterity: Fernando Pessoa's Poetry}

Glória Maria Monteiro de Carvalho

Universidade Católica de Pernambuco-UNICAP, Recife, Pernambuco / Brasil gmmcarvalho@uol.com.br

Maria de Fátima Vilar de Melo

Universidade Católica de Pernambuco-UNICAP, Recife, Pernambuco / Brasil mfvmelo@uol.com.br

Resumo: Este artigo tem por objetivo colocar em discussão a equivocidade concebida como condição incontornável da língua, com fundamento no trabalho de Jean Claude Milner: O amor da língua (2012) que toma, como ponto de partida, as noções lacanianas de sujeito do inconsciente e de lalíngua (lalangue). Com esse objetivo, destaca-se que o caráter equívoco da palavra surpreende o sujeito, dividindo-o, ou melhor, revelando-o em seu exílio de si mesmo. Nessa perspectiva, entraram em cena fragmentos da poesia de Fernando Pessoa cuja análise deu especial visibilidade à poesia como lugar privilegiado onde se aloja o equívoco da língua, ao mesmo tempo em que vislumbrou o estatuto do sujeito-suporte desse equívoco como sendo um sujeito dividido marcado por sua condição de alteridade.

Palavras-chave: equivocidade; língua; lalíngua (lalangue), poesia.

Abstract: This article aims to discuss equivocity, conceived as an unavoidable condition of language, based on the work by Jean Claude Milner: L'amour de la langue (2012) which takes as its starting point 
Lacanian notions of the unconscious subject and lalangue. With this objective, it was highlighted that the equivocal character of the word surprises the subject, dividing him/her, or rather revealing him/her in his/her self-exile. In this perspective, fragments of Fernando Pessoa's poetry took place and whose analysis brought special visibility to poetry as a privileged place in which language equivocity is held, as it focused the statute of the support-subject of such equivocity as being a divided subject marked by his/her condition of alterity.

Keywords: equivocity; language; lalangue, poetry.

Recebido em 28 de outubro de 2017

Aprovado em 11 de janeiro de 2018

\section{Introdução}

Pretendemos, neste artigo, colocar em discussão o chamado caráter equívoco da língua, considerando que esse caráter está atrelado ao fato de que existe, em qualquer língua, como condição incontornável, a possibilidade de um duplo sentido, de um mal-entendido. Por sua vez, assumimos que, para ser concebida de forma consistente, tal condição teria, como fundamento, o sujeito da psicanálise, sujeito do inconsciente. Dizendo de outro modo, podemos falar em equívoco, como uma não coincidência da palavra consigo mesma, ou melhor, como um sentido que se refrata em outro sentido (ou em outros sentidos), supondo-o como um efeito provocado pela palavra sobre um sujeito também não coincidente consigo mesmo, portanto, marcado pela alteridade, um sujeito dividido, em consonância com a proposta psicanalítica. De acordo com Lacan (1985), considerando a linguagem não como uma instituição, nem do ponto de vista teórico, impõe-se a nós o fato de que as diversas maneiras de dizer um enunciado submetem a palavra ao movimento incontrolável e incontornável de produzir vários sentidos.

A título de abordarmos essa questão, recorremos a Jean Claude Milner - notadamente ao livro O Amor da Língua (2012) - que concebe o equívoco, com base na proposta lacaniana, como a condição da palavra de poder assumir vários sentidos, ao mesmo tempo, podendo assumir sentidos contraditórios. 
Já Platão (2008), em Fedro, caracterizou, magistralmente, esse movimento da palavra, através do conceito de fharmacon. De acordo com Marilena Chaúi (1999), nessa obra, Platão afirmava, por meio de Sócrates, que a linguagem é um pharmacon - palavra grega que em português se traduz por poção, tendo três sentidos: remédio, veneno e cosmético.

No primeiro sentido, a linguagem seria um medicamento ou um remédio para o conhecimento. Pode ser um veneno quando, pela sedução das palavras, faz-nos aceitar, fascinados, o que vimos ou lemos sem indagarmos se tais palavras são verdadeiras ou falsas. A linguagem pode ser ainda cosmético, maquiagem ou máscara. Enfim, a linguagem pode ser conhecimento-comunicação ou dissimulação, encantamentosedução. Assim, a própria concepção de linguagem, nessa perspectiva, seria constituída pelo equívoco do termo que a nomeia.

Tentaremos, portanto, nesta discussão, abordar a noção de equivocidade da palavra, exemplificando-a por meio de fragmentos de textos poéticos de Fernando Pessoa, procurando indicar que essa noção se suporta na concepção psicanalítica de sujeito dividido.

\section{0 equívoco de lalangue}

No campo da linguística, Milner (2012) possui um trabalho inovador e consistente que põe em relevo a noção de equivocidade da língua, assumindo, como eixo teórico, os conceitos lacanianos de sujeito do inconsciente e de lalíngua (lalangue). ${ }^{1}$ Esse termo (lalíngua) denomina o lugar dos equívocos, isto é, a existência, em toda língua, de um registro que a condena ao equívoco. Dentre as características de lalangue, aquele autor destaca sua propriedade de se fazer presente em toda e qualquer língua, não pertencendo exclusivamente a nenhuma, impedindo-as, a todas, de fazerem Um. Assim, toda língua encerra tal predicado, na medida em que inclui a função de sujeito em suas operações, na medida em que contém a matéria-prima para acusar imprecisões e provocar equivocidades e mal-entendidos: lalangue é, assim, o registro responsável por impelir toda língua, seja qual for, ao equívoco.

\footnotetext{
${ }^{1} \mathrm{O}$ termo lalangue consiste numa invenção de Lacan (1997) decorrente de um ato falho. Referindo-se ao Vocabulário de Psicanálise de Lagache, Lacan diz Vocabulário de Filosofia que foi escrito por Lalande, produzindo-se, então, lalangue. Por sua vez, nessa invenção, é de fundamental importância a sonoridade entre lalangue and lalation.
} 
Milner (2012) realça, então, que a língua materna consiste na mais direta e evidente configuração da lalangue, conforme pontua Lacan (1975), ao assinalar que não é em vão que ela recebe tal classificação. Isso se deve, antes, ao fato de que essa lalangue está, privilegiadamente, suportada na materialidade que a língua materna lhe oferece, apesar de exorbitar, em muito, os termos que ela lhe empresta. Lacan (1975) afirma haver uma articulação original e indissociável entre a língua materna e os termos lalangue e sujeito. Ele pontua que um sujeito de linguagem recebe lalangue diretamente de sua mãe, ou de quem cumpre tal função, e que há uma inegável mediação da materialidade implicada na língua materna (a língua que é, neste momento, falada pela mãe) em tal operação.

Nesse sentido, observamos que Lacan, em sua conferência, proferida em Genebra, sobre o sintoma (1985), para falar da lalíngua (lalangue), remete-se aos estoicos, destacando que são eles os autores da descoberta. Afirma esse autor que, bem antes de Freud, os estoicos puderam perceber que a linguagem, essa linguagem que não tem nenhuma existência teórica, intervém sempre sob a forma daquilo que ele denominou por meio de uma palavra, a mais próxima possível da palavra lalação (lallation): lalíngua (lalangue). Para entendermos melhor essa concepção lacaniana, faremos uma tradução livre do texto referido:

Lalíngua (lalangue), os antigos, após Esopo, tinham muito bem se apercebido que era absolutamente capital. Existe em relação a isto uma fábula bem conhecida, mas que ninguém se apercebe, que não é de jeito nenhum por acaso que na lalíngua (lalangue) qualquer que ela seja e da qual alguém recebeu a primeira impressão, uma palavra é equívoca. Não é certamente por acaso que a palavra $n e^{2}$ se pronuncia de uma maneira equívoca com a palavra noeud (nó). Não é de modo algum por acaso que a palavra pas que em francês redobra a negação, ao contrário de muitas línguas, designa também um pas (passo). Isto não quer dizer que a língua constitua de alguma maneira um patrimônio. É inteiramente certo que é na maneira pela qual foi falada e também entendida por tal e tal pessoa, na sua particularidade, que alguma coisa em seguida sairá de novo em sonhos, em todas as hesitações (vacilos, enganos), em toda maneira de dizer. (LACAN, 1985, p. 5, tradução nossa)

\footnotetext{
${ }^{2}$ Primeira partícula de negação da língua francesa, que se realiza com o ne antes do verbo e o pas após.
} 
Nessa perspectiva, a equivocidade seria constitutiva de qualquer língua, podendo ser apreendida no momento em que a palavra é arrancada do círculo de referência ordinária (MILNER, 2012), adquirindo, simultaneamente, vários sentidos ou, em outros termos, fazendo com que uma locução verbal seja, ao mesmo tempo, ela mesma e uma outra, suspendendo, portanto, sua identidade.

A esse respeito, invocamos Brisset (1900, p. 702, apud PORGE, 2013, p. 58) que, no seu livro La Science de Dieu ou la création de l'homme, mostra que uma mesma série fônica (da língua francesa) pode adquirir, conforme sua escrita, vários sentidos, como no exemplo seguinte:

Les dents, la bouche. ("os dentes, a boca")

Les dents la bouchent. ("os dentes a entopem")

L'aidant la bouche. ("ajudando a boca")

L'aide en la bouche. ("a ajuda na boca")

Laides em la bouche. ("feios na boca")

Laid dans la bouche. ("feio na boca")

Lait dans la bouche. ("leite na boca")

L'est dam le à bouche. ("é a barragem à boca")

Les dents-là bouche. ("os dentes la na boca")

(BRISSET, 1900, p. 702, apud PORGE, 2013, p. 58)

$\mathrm{O}$ autor define, assim, a grande Lei ou a chave da palavra:

Existem, no discurso, inúmeras Leis, desconhecidas até agora, entre as quais a mais importante é que um som ou uma cadeia de sons idêntica, inteligível e clara, possa exprimir coisas diferentes, por uma modificação na maneira de escrever ou de compreender esses nomes ou palavras. Todas as ideias enunciadas com sons semelhantes têm uma mesma origem e se relacionam todas, dentro de seu princípio, a um mesmo objeto. (BRISSET, 1900, apud PORGE, 2013, p. 58)

Em relação aos sons idênticos (ou semelhantes) que possam exprimir coisas diferentes a partir de uma modificação na maneira de escrever ou de compreender os nomes, ou melhor, em relação à condição de equívoco da língua, Porge (2014) lança mão da noção de eco que consiste no envio de uma ressonância comum a várias palavras. Diz esse autor: 
Pode-se também dizer que o eco participa da interpretação analítica, na medida em que, para que ele opere, "é preciso que haja alguma coisa no significante que ressoe”. A razão é réson. O eco, sem que sua presença seja facilmente localizável, e sem dúvida por isso, faz ressoar a fala; a esse título, ele pode, na linguagem, confundir-se com ela. (PORGE, 2014, p. 22)

Na prática clínica na linha psicanalítica, a noção de equívoco é fundamental e temos, nessa prática, um exemplo fornecido por Pommier (2011) de sua clínica com crianças. Esse autor cita o caso de uma criançacom dificuldades na escrita - que produziu um conjunto de letras: LELIIES (literalmente ilegível), ${ }^{3}$ considerando-o como o seu nome próprio. Sem ter a intenção de fazer uma interpretação, esse autor se contentou em ler, diz ele, esse conjunto de letras: Le lit y est-ce e, somente no momento dessa leitura, pareceu que isso queria dizer "alguma coisa", ou melhor, isso queria dizer a questão, o sintoma do menino. Conforme diz o autor, retroativamente, pareceu-lhe certo que essa leitura que surpreendeu tanto a ele, quanto ao menino, teve um valor de interpretação. A surpresa estaria, portanto, indicando que analista e analisando foram apanhados/ capturados pelo equívoco de uma série sonora. "A melhora surpreendente da escrita, que devia suceder essa sessão, permite pensar que a leitura de leliies teve um valor de interpretação”. (POMMIER, 2011, p. 69)

Assim, conforme diz Lacan (1975), no trecho supracitado, como a língua não é um patrimônio, quando ela é falada dá lugar à produção e ao retorno do equívoco. Segundo Pommier (2004), para falar, é preciso esquecer o som, é preciso recalcar o som dos objetos para que ele se transforme em letra e participe da formação do significante. Afirma, então: "Se digo 'lobo' vocês pensarão no animal e esquecerão a música do som ' $l o$ ' com a qual poderíamos cantarolar' (POMMIER, 2004, p. 124). É preciso, então, esquecer/recalcar ${ }^{5}$ os sons das palavras, e acrescentamos que isso ocorre juntamente com o esquecimento/recalque do equívoco que advém quando nossa atenção se prende a esses sons. Nesse sentido, falar seria reconduzir, continuamente, o recalque do equívoco ou, para

\footnotetext{
${ }^{3}$ Esse conjunto de letras se inicia com um B invertido.

${ }^{4}$ A cama está aí?

${ }^{5} \mathrm{O}$ recalque ou recalcamento, conceito freudiano, consiste no "Processo de afastamento das pulsões às quais é rejeitado o acesso à consciência”. (CHEMAMA, 1995, p. 185)
} 
usar a expressão desse autor, seria uma contínua recondução do recalque originário.

Abordaremos, a seguir, a poesia de Fernando Pessoa a qual constitui um lugar privilegiado onde o equívoco ganha visibilidade.

\section{O equívoco como ponto de poesia: um exemplo em Fernando Pessoa}

Com fundamento nas colocações anteriores, pode-se dizer que, diferentemente do lugar ocupado pelo equívoco na psicanálise, do ponto de vista da ciência linguística, na elaboração de uma teoria sobre a linguagem, é necessário o pressuposto de identidade/univocidade de uma locução verbal para que se possa emitir um julgamento de gramaticalidade, ou melhor, para que haja uma decidibilidade no que toca a oposição correto-incorreto que pode, também, ser lida como certoerrado, aceitável-inaceitável. Essa decidibilidade pretende garantir a consistência e a completude imaginárias da língua, mais especificamente, da gramática. A esse respeito, Milner afirma:

A gramática representa a língua, mas não através de uma escrita simbólica; em vez disso, dela constrói uma imagem. A exigência de completude ganha, então, uma coloração imaginária e se transpõe em termos de totalidade: totalidade qualitativa, isto é, perfeição (por isso que toda gramática é simultaneamente um elogio à língua descrita); totalidade quantitativa (por isso que só se concebe uma gramática completa). (2012, p. 41)

Mais adiante, completa: "Quanto à consistência, ela é o que se requer das escritas: que as sequências permitidas não se mostrem contraditórias" (MILNER, 2012, p. 42). No entanto, conforme destaca Milner (2012), o equívoco, ao aparecer através dos estratos que formam a totalidade imaginária da gramática, desfaz esses estratos, dando visibilidade à língua na sua condição inarredável de ser equívoca, de ser incompleta. Com base em tal condição, esse autor caracteriza o equívoco como ponto de cessação. Trata-se de um ponto de cessação da (suposta) totalidade linguística, de seus estratos, de sua divisão entre certo e errado, entre som e sentido, entre menção e uso. Nos próprios estratos da língua, esses pontos de cessação vêm à tona, por exemplo, por meio dos pronomes pessoais, dos performativos, dos insultos, exclamações. A esse respeito conclui o autor: 
Tanto que, tendo em vista a própria língua, não faltam pontos em que a estratificação se suspende. O inventário, apesar de incompleto, não é desconhecido: pronomes pessoais, performativos, insultos, exclamações - todos elementos cuja definição, em menção, implica circularmente o uso do definiendum; cujo sentido só se explica inteiramente por um recurso ao proferimento do próprio som. Sabe-se, afinal, que eu designa aquele que diz "eu"; que jurar é dizer "eu juro" etc. (MILNER, 2012, p. 19, grifo do autor)

Podemos também chamar esse ponto de cessação de ponto de indecidibilidade, uma vez que não se pode decidir, com segurança, sobre o sentido ou sentidos predeterminados a serem atribuídos a uma produção verbal, embora se reconheça tal produção como pertencendo a uma língua. Na mesma obra, o referido autor denomina-o também ponto de poesia, na medida em que o equívoco se faz presente, de forma magistral, nessa manifestação artística que é, por ele, destacada como um incessante retorno do equívoco.

Nessa perspectiva, ao que tudo indica, Fernando Pessoa soube, como poucos, fazer uso da equivocidade da língua, subvertendo, transgredindo o sentido comum da palavra, valorizando, inclusive, seus sentidos contraditórios. A esse respeito, Jakobson (1973), ao realizar uma análise do poema Ulysses, do poeta português, destaca essa valorização da contradição, afirmando que "[...] o traço característico de todo o poema é uma tensão constante entre afirmação e negação e os contrários se transformam em contradição" (JAKOBSON, 1973, p. 470, tradução nossa). A tensão entre afirmação e negação, trazendo à tona a marca da contradição, vem à tona no início da primeira estrofe do poema citado, entre os termos nada e tudo e, na última estrofe, entre vida e morte:

\section{PRIMEIRO/ULYSSES}

O MYTHO é o nada que é tudo.

O mesmo sol que abre os céus

É um mytho brilhante e mudo -

O corpo morto de Deus,

Vivo e desnudo.

Este, que aqui aportou,

Foi por não ser existindo.

Sem existir nos bastou.

Por não ter vindo foi vindo

E nos criou. 
Assim a lenda se escorre

A entrar na realidade.

E a fecunda-la decorre.

Em baixo, a vida, metade

De nada, morre.

(PESSOA, 1976, p. 72, grifo nosso)

Essa equivocidade em seu aspecto de contradição se faz especialmente visível no poema intitulado Tabacaria - incluído no título geral Ficções do interlúdio/poesias de Álvaro de Campos (PESSOA, 1976, p. 301-423), um dos poemas mais divulgados do poeta português -, atravessando suas várias estrofes das quais selecionaremos as que se seguem, a título de ilustração:

TABACARIA

$[\ldots]$

Janelas do meu quarto,

Do meu quarto de um dos milhões do mundo que ninguém sabe quem é

(E se soubessem quem é, o que saberiam?),

Das para o mistério de uma rua cruzada constantemente por gente,

Para uma rua inacessível a todos os pensamentos,

Real, impossivelmente real, certa, desconhecidamente certa,

Com o mistério das coisas por baixo das pedras e dos seres,

Com a morte a pôr umidade nas paredes e cabelos brancos nos homens,

Com o destino a conduzir a carroça de tudo pela estrada de nada. (PESSOA, 1976, p. 362, grifo nosso)

$[\ldots]$

Falhei em tudo.

Como não fiz propósito nenhum, talvez tudo fosse nada.

A aprendizagem que me deram,

Desci dela pela janela das traseiras da casa.

Fui até ao campo com grandes propósitos.

Mas lá encontrei só ervas e árvores,

E quando havia gente era igual à outra.

Saio da janela, sento-me numa cadeira. Em que hei de pensar?

(PESSOA, 1976, p. 363, grifo nosso) 
$[\ldots]$

Mas ao menos fica da amargura do que nunca serei

A caligrafia rápida destes versos,

Pórtico partido para o impossível.

Mas ao menos consagro a mim mesmo um desprezo sem lágrimas, Nobre ao menos no gesto largo com que atiro

A roupa suja que sou, sem rol, pra o decurso das coisas,

E fico em casa sem camisa.

[...]

(PESSOA, 1976, p. 364, grifo nosso)

O jogo entre o tudo e o nada se sobressai na primeira estrofe recortada: "Com o destino a conduzir a carroça de tudo pela estrada de nada" e na terceira estrofe recortada: "Como não fiz propósito nenhum, talvez tudo fosse nada". Indica-se, também, a contradição entre possível e impossível, na primeira estrofe recortada, implicada em termos como o real (no sentido de realidade) e o impossível, na expressão "impossivelmente real" e o certo e o desconhecido, na expressão "desconhecidamente certa". Destaca-se, ainda, na terceira estrofe recortada, esse jogo entre possível e impossível, quando, referindo-se à "caligrafia rápida desses versos", no verso, magistralmente, composto por uma aliteração: "Pórtico partido para o impossível", aponta-se para a dimensão equívoca do termo Pórtico. Segundo o Dicionário de Houaiss, esse termo tanto pode significar "galeria cujo teto ou abóbada são sustentados por colunas ou por arcada" (HOUAISS, 2001, p. 2267) como, em seu sentido figurado, pode significar "entrada, ingresso, acesso a algo grandioso e difícil" (HOUAISS, 2001, p. 2267). Etimologicamente, seu segmento port vem do latim porta, ae, significando passagem. Por sua vez, o termo partido tanto quer dizer quebrado, quanto saído de algum lugar; segundo o mesmo dicionário citado, etimologicamente, é também particípio passado decorrente do verbo latino: partire que significa partir, dividir, distribuir.

Podemos dizer, então, que essa valorização da equivocidade, especialmente da contradição emerge dos escritos de Pessoa, fazendose especialmente visível em alguns poemas. Desses poemas, destaca-se, além dos já citados como exemplo, aquele intitulado Passos da cruz do qual Durval Checchinato - em seu texto: $O$ inconsciente em Fernando Pessoa (s/d) - recorta algumas estrofes e, por meio de cuidadosa análise, procura exemplificar o relacionamento do poeta com as manifestações, os retornos do seu inconsciente. Transcrevemos, então, as seguintes estrofes: 


\section{XIII}

Emissário de um rei desconhecido,

Eu cumpro informes instruções de além,

As bruscas frases que aos meus lábios vêm

Soam-me a um outro e anômalo sentido...

Inconscientemente me divido

Entre mim e a missão que o meu ser tem,

E a glória do meu Rei dá-me o desdém

Por este humano povo entre quem lido....

(PESSOA, 1976, p. 128)

De acordo com a análise de Checchinato $(\mathrm{s} / \mathrm{d})$, o relacionamento do poeta com seu inconsciente, no poema em foco, destaca-se por meio de dois fenômenos: a equivocidade da palavra e a divisão do sujeito, isto é, o exílio de si mesmo, a exterioridade em relação a si mesmo. Tais fenômenos (a divisão e a equivocidade), na perspectiva lacaniana, seriam indissociáveis, na medida em que, conforme já colocado antes, o equívoco estaria fundamentado em um sujeito dividido, exilado de si mesmo, um sujeito que consiste em um outro de si mesmo. Na perspectiva de Milner:

Em sentido estrito, o elemento linguístico, e mais geralmente estrutural, não é idêntico a si; por um lado, porque não tem si, por outro, porque a identidade cedeu o espaço à oposição, a qual o atravessa. (MILNER, 2003, p. 169, tradução nossa)

[...] Tendo-se admitido que todo termo estrutural como tal é não idêntico a si, o sujeito é o termo da cadeia que suporta 'o não idêntico a si' de todo termo da cadeia. Sabe-se que na cadeia mínima toda propriedade de termo é termo (MILNER, 2003, p. 169-170, tradução nossa)

Como exemplo de equivocidade destacada na análise em questão, a palavra informe tanto é informação, comunicação, mensagem, como é algo sem forma, tosco, deformado, desde que in é uma preposição latina que indica direção, sendo aplicada com verbos de movimento, mas in também significa negação. Nessa perspectiva, Pessoa capta a maneira contraditória pela qual o inconsciente se manifesta, sendo que essa contradição se reduplica na expressão: informes instruções. Assim, as palavras são informes, porque não informam, mas, paradoxalmente, são instruções, isto é, ensinam. Por sua vez, de acordo com Checchinato 
(s/d), a intuição poética de Pessoa revela a descoberta desconcertante da divisão do sujeito, ou seja, de uma ausência de si mesmo, de um exílio de si mesmo, por exemplo, nos versos: "Inconscientemente me divido" "Entre mim e a missão que o meu ser tem".

Essa divisão - esse exílio de si mesmo - é vislumbrada ainda em Tabacaria, na estrofe que se segue:

$[\ldots]$

Fiz de mim o que não soube,

E o que podia fazer de mim não o fiz.

O dominó que vesti era errado.

Conheceram-me logo pelo que não era e não desmenti, e perdi-me.

Quando quis tirar a máscara,

Estava pegada à cara.

Quando a tirei e me vi ao espelho.

Já tinha envelhecido.

Estava bêbado, já não sabia vestir o dominó que não tinha tirado.

Deitei fora a máscara e dormi no vestiário

Como um cão tolerado pela gerência

Por ser inofensivo

E vou escrever esta história para provar que sou sublime.

(PESSOA, 1976, p. 365, grifo nosso)

Assim, a metáfora dominó - "O dominó que vesti era errado" - no sentido de fantasia, de máscara que fica pegada à cara e não se consegue tirar, estaria indicando a ilusão que se constrói sobre si mesmo; nessa perspectiva, o verso "Estava bêbado, já não sabia vestir o dominó que não tinha tirado", com a contradição implicada nesse verso - vestir a roupa que não se tirou -, poderia estar indicando que, ao deixar de alimentar uma ilusão a respeito do que é, a respeito de si mesmo, o poeta se perdeu, caiu em um desconhecimento de si, ou caiu em um nada o qual seria equiparado a um "cão tolerado pela gerência por ser inofensivo". Em última análise, o poeta teria chegado a se confrontar com a condição de que é um estrangeiro em relação a si mesmo, à condição de um exílio de si mesmo, enfim à própria inexistência de um si mesmo, conforme já foi indicado em outros poemas.

Sobre essa condição de estrangeiro em relação a si mesmo, convém citar Ruffato (2012, p. 7) que, na apresentação do livro, por ele organizado, Quando fui outro, de Fernando Pessoa, afirma: 
Reunindo poemas, fragmentos do "romance sem ação" Livro do Desassossego, ensaios e cartas, Quando fui outro ressalta a impressionante unidade temática da obra de Pessoa - este sentirse "estrangeiro aqui como em toda parte" - e a absoluta simbiose entre vida e arte $[\ldots]$.

Outro exemplo pode ser indicado nas duas primeiras estrofes de um poema incluído no título geral Cancioneiro (PESSOA, 1976, p. 103194), a seguir transcritas:

ENTRE O SONO e o sonho,

Entre mim e o que em mim

É o quem eu me suponho

Corre um rio sem fim.

Passou por outras margens,

Diversas mais além,

Naquelas várias viagens

Que todo o rio tem.

[...]

(PESSOA, 1976, p.171)

Assim, a divisão, o exílio do sujeito em relação a si mesmo é metaforicamente expresso por um rio - em seu contínuo movimento ("várias viagens") - que ocupa o lugar do intervalo "entre mim" e o "quem eu me suponho". Tal divisão, por sua vez, manifesta-se mais claramente em um verso de um poema (assinado com o heterônimo de ÁLVARO DE CAMPOS), incluído no título geral Ficções do interlúdio/ poesias de Álvaro de Campos (PESSOA, 1976, p. 301-423): “Sou o intervalo entre o que desejo ser e os outros me fizeram", no recorte da estrofe transcrito a seguir:

Começo a conhecer-me. Não existo.

Sou o intervalo entre o que desejo ser e os outros me fizeram,

Ou metade desse intervalo, porque também há vida...

Sou isso enfim...

Apague a luz, feche a porta e deixe de ter barulhos de chinelos no corredor.

Fique eu no quarto só com o grande sossego de mim mesmo.

É um universo barato.

(PESSOA, 1976, p. 413) 
Em relação à divisão do sujeito focalizada em termos de um intervalo que expressa tal divisão, não poderíamos deixar de fazer referência ao seguinte fragmento ${ }^{6}$ recortado do Livro do desassossego:

Nuvens... Existo sem que o saiba e morrerei sem que o queira. Sou o intervalo entre o que sou e o que não sou, entre o que sonho e o que a vida fez de mim, a média abstrata e carnal entre coisas que não são nada, sendo eu nada também. Nuvens... Que desassossego se sinto, que desconforto se penso, que inutilidade se quero! (PESSOA, 1986, p. 166, grifo nosso)

Indicamos, nesse fragmento, a equivocidade da palavra nuvens destacada em um contínuo movimento entre polos opostos: entre a vida e a morte, entre o sonho e o que a vida faz do ser humano. Convém notar, nesse movimento equívoco da palavra, a sua dimensão contraditória, no instante em que o autor se refere à média que é, ao mesmo tempo, abstrata e carnal, sendo essa média calculada entre as coisas que não são nada e, mais ainda, em relação a alguém que também é nada, apontando, portanto, para a condição de exilado de si mesmo.

Fernando Pessoa, ao que tudo indica, procura expressar o máximo desse exílio, com os heterônimos: a criação de vários nomes próprios. Etimologicamente, heteronímia vem do grego héteros, $a$, on $=$ outro, diferente + ónoma, atos $=$ nome, significando diferentes nomes (HOUAISS, 2001). Segundo Cavalcanti Filho, em seu sentido estrito, preciso, heterônimos consistem em "pessoas imaginárias a quem se atribui uma obra literária com autonomia de estilo em relação ao autor" (2011, p. 234). Nesse sentido, o poeta teria criado apenas três heterônimos: Alberto Caeiro, Ricardo Reis e Álvaro de Campos. Considerando, entretanto, o termo em seu sentido amplo de personalidades, máscaras ou afins, Cavalcanti Filho (2011, p. 240) contabilizou 127, destacando, contudo, que esse número pode variar de acordo com o critério utilizado.

Conforme Harari (2001), quando um autor inventa um outro autor, o primeiro já trabalha atrás do desconhecimento de sua identidade. Nessa perspectiva, afirma esse autor que a heteronímia passa pela condição do autor fora de sua pessoa. Os heterônimos de Fernando Pessoa, portanto, aparentemente, indicam a condição de alteridade do sujeito, a condição de se instalar fora de sua pessoa, ou melhor, de se instalar na posição de um outro.

\footnotetext{
${ }^{6}$ Embora não se trate propriamente de poemas, essa obra consiste em escritos poéticos reunidos por Bernardo Soares, semi-heterônimo de Fernando Pessoa.
} 


\section{Mais algumas palavras}

Retomando o que foi posto ao longo deste artigo, destacamos que o equívoco, como condição de qualquer língua, precisa ser domado, controlado, ou seja, excluído dos estudos da língua, para que se possa construir uma teoria linguística e, mais especificamente, uma gramática. Por sua vez, tal condição aparece/retorna em alguns lugares dessa construção e em alguns pontos das várias manifestações da língua, ou melhor, aparece em toda maneira de dizer.

No entanto, haveria lugares em que a dimensão de equívoco se faria visível de forma privilegiada, dentre os quais a poesia da qual recortamos, a título de ilustração, fragmentos poéticos de Fernando Pessoa, embora convenha repetir que essa dimensão pode se fazer visível em qualquer tipo de texto, na medida em que ela consiste numa condição incontornável da língua.

Enfim, podemos dizer que a análise de fragmentos de textos do poeta português exemplificou magistralmente o ponto de equívoco ou ponto de poesia, dando, portanto, visibilidade à divisão do sujeito em seu exílio de si mesmo que teria se tornado especialmente visível, por meio da criação dos heterônimos com os quais o poeta assinou sua produção.

Assim, a apreensão do equívoco se apoia em um sujeito dividido, sujeito da psicanálise que se vê capturado pelo efeito de surpresa provocado por essa apreensão, o qual estaria revelando, nessa captura, sua condição de alteridade, seu exílio de si mesmo, inclusive, colocando em questão a existência de um si mesmo.

Fernando Pessoa, de sua parte, deu especial visibilidade à poesia como lugar privilegiado onde se aloja o equívoco, ao mesmo tempo em que vislumbrou a condição do sujeito-suporte desse equívoco como sendo marcada pelo "intervalo entre o que desejo ser e os outros me fizeram" (PESSOA, 1976, p. 413), enfim, pelo "intervalo entre o que sou e o que não sou" (PESSOA, 1986, p. 166).

\section{Agradecimentos}

Este artigo faz parte de Projeto de Pesquisa financiado pelo CNPq pelo que formulamos nossos agradecimentos. 


\section{Referências}

CAVALCANTI FILHO, J. P. Fernando Pessoa: uma quase autobiografia. Rio de Janeiro: Record, 2011.

CHAUÍ, M. Convite à filosofia. São Paulo: Editora Ática, 1999.

CHECCHINATO, D. O inconsciente em Fernando Pessoa. [Artigo publicado pela Associação Campinense de Psicanálise]. Disponível em: $<\mathrm{http}$ ://www.acpsicanalise.org.br/docs/o-inconsciente-em-fernandopessoa-durval-checchinato.pdf (s/d)>. Acesso em: 3 jul. 2014.

CHEMAMA, R. Dicionário de psicanálise. Porto Alegre: Artes Médicas, 1995.

HARARI, R. O que acontece no ato analítico. Rio de Janeiro: Companhia de Freud, 2001.

HOUAISS, A. Dicionário da língua portuguesa. Rio de Janeiro: Editora Objetiva, 2001.

JAKOBSON, R. Questions de poétique. Paris: Éditions du Seuil, 1973.

LACAN, J. Conférence à Geneve sur le symptome (1975). In: Le Blocnotes de la psychanalyse, Genf, n. 5, p. 5-23, 1985. Disponível em: <http// www.ecole-lacanienne.net/>. Acesso em: 20 jun. 2015.

LACAN, J. Encore: Seminaire XX (1972-1973). Paris: Association Lacanienne Internationale, 1975.

LACAN, J. O saber do psicanalista: Seminário (1971-1972). [Publicação para circulação interna]. Recife: Centro de Estudos Freudianos do Recife, 1997.

MILNER J.C. El periplo estructural: figuras y paradigma. Buenos Aires: Amorrortu, 2003.

MILNER, J. C. O amor da língua. Campinas: Editora da Unicamp, 2012.

PESSOA, F. Livro do desassossego. São Paulo: Editora Brasiliense, 1986. Disponível em: <http://www3.universia.com.br/conteudo/literatura/ Livro_do_desassossego_fernando_pessoa.pdf $>$. Acesso em: 2 fev. 2016. PESSOA, F. Obra poética. Rio de Janeiro: Nova Aguilar, [1928] 1976. 
PESSOA, F. Quando fui outro. Antologia organizada por L. Ruffato. Rio de Janeiro: Editora Objetiva, 2012.

PLATÃO. Diálogos III (socráticos). Tradução de Edson Bini. São Paulo: EDIPRO, 2008.

POMMIER, G. Da passagem literal do objeto ao moedor do significante. In: MELMAN, C. et al. O significante, a letra e o objeto. Rio de Janeiro: Companhia de Freud, 2004. p. 119-126.

POMMIER, G. Problemas clínicos da escrita. In: LIER-DE VITTO, M.F.; ARANTES, L. (Org.). Faces da escrita: linguagem, clínica, escola. São Paulo: Mercado de Letras, 2011. p. 53-74.

PORGE, E. O inapanhável objeto do savoir-faire na análise. Estudos de Psicanálise, Belo Horizonte, n. 40, p. 49-62, 2013. Disponível em: $<$ http://www.cbp-rj.org.br/erik.pdf $>$. Acesso em: 20 jun. 2015.

PORGE, E. Voz do eco. Campinas: Mercado de Letras, 2014.

RUFFATO, L. Apresentação. In: PESSOA, F. Quando fui outro. Antologia organizada por L. Ruffato. Rio de Janeiro: Editora Objetiva, 2012. 